\title{
Ternary complex [Sm(acac) (5-Br-2,2 -bpy)] for the solution-processed white polymer light-emitting diode (WPLED)
}

\author{
Jiaxiang Liu ${ }^{a, 1}$, Wentao $\mathrm{Li}^{\mathrm{a}, 1}$, Baowen Wang ${ }^{\mathrm{a}}$, Mingfeng Tan ${ }^{\mathrm{a}}$, Yani He ${ }^{\mathrm{a}}$, Tiezheng Miao ${ }^{\mathrm{a}}$, Xingqiang \\ $\mathrm{Lü}^{a, *}$, Guorui Fu ${ }^{a, * *}$, Hongshan He ${ }^{\text {b,***}}$ \\ ${ }^{a}$ School of Chemical Engineering, Shaanxi Key Laboratory of Degradable Medical Materials, Northwest University, Xi'an, 710069, Shaanxi, China ${ }^{\text {b }}$ \\ Department of Chemistry, Eastern Illinois University, Charleston, IL, 61920, USA
}

\section{ARTICLEINFO}

Keywords:

Tris-6-diketonate-Sm ${ }^{3 \mathrm{~b}}$-complex

Dichromatic integration

Direct white-light

White polymer light-emitting diode

\section{A B S T R A C T}

In consideration of the $\mathrm{Sm}^{3 \mathrm{~b}}$-centered characteristic orange-light as the ideal color-primary component toward a dichromatic

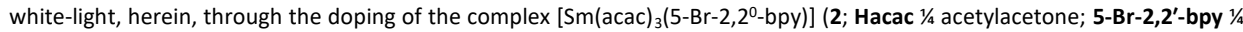
5-Br-2,20-bipyridine) into the PVK (PVK 1/4 poly(N-vinyl-carbazole)) host, the obtained PVK@2 film (10:1, wt/wt) exhibits the straightforward solid-state white-light $\left(\Phi_{\mathrm{PL}} 1 / 46.7 \%\right)$. Further using the PVK@2 film (10:1; wt/wt) as the emitting layer, its singlecomponent solution-processed WPLED gives the electroluminescent performance ( $L^{\operatorname{Max}}$ of $360.9 \mathrm{~cd} / \mathrm{m}^{2}, \eta^{\mathrm{Max}}{ }_{\mathrm{c}}$ of $\left.1.08 \mathrm{~cd} / \mathrm{A}\right)$ satisfactory enough for portable full-color flat displays.

\section{Introduction}

Contributing from the receptive "antenna" effect [1], the Sm ${ }^{3 b}$-centered orange-light $\left({ }^{4} \mathrm{G}_{5 / 2} \rightarrow{ }^{6} \mathrm{H}_{J / 2} ; J 1 / 45,7,9\right.$ or 11) [2] can be sensitized through the Laporte- and spin-allowed ligand-centered transition $\left({ }^{\circ} \mathrm{S} \rightarrow{ }^{1} \mathrm{~S}\right)$ followed by the inter-system crossing (ISC; $\left.{ }^{1} \mathrm{~S} \rightarrow{ }^{1} \mathrm{~T}\right)$ and the ${ }^{1} \mathrm{~T} \rightarrow \mathrm{Sm}^{3 p *}$ energy transfer for one certain organo-Sm ${ }^{3 p}$ complex. Especially toward the high efficiency [3] of its $\mathrm{Sm}^{3 \mathrm{~b}}$-centered high-purity orange-light, the selection of a suitable organic ligand is of paramount importance, from which, the strong absorption, the maximized energy transfer and the minimized radiationless deactivation should be simultaneously ensured [4]. Till now, compared with the concerted efforts to vacuum-deposited [5] or solution-processed [6] orange-light organic/polymer light-emitting diodes (OLEDs/PLEDs), the realization of reliable WOLEDs/WPLEDs using organo- $\mathrm{Sm}^{3 p}$ complex as the emitter lags far behind [7], despite the theoretically dichromatic, trichromatic or tetrachromatic white-light production [8] smoothly incorporated with the $\mathrm{Sm}^{3 \mathrm{~b}}$-centered color-primary orange-light.

As a matter of fact, among organo-Sm ${ }^{3 b}$ hybrid materials, although $\mathrm{Sm}^{3 \mathrm{p}_{-}}$ relative metal-organic frameworks (MOFs) or coordination polymers [9], are prevalent white-light-emitting solid-state materials promising for white LEDs (WLEDs) [10], the inherent deficiency of their processing (vacuum-deposition or solution-process) inability, limits the utilization in WOLEDs/WPLEDs. By contrast, available of the necessary film-formation for sublimable smallmolecule organo-Sm ${ }^{3 b}$ complexes or organo- $\mathrm{Sm}^{3 \mathrm{~b}}$-incorporated polymers, their WOLEDs/WPLEDs with the $\mathrm{Sm}^{3 \mathrm{~b}}$-centered orange-light as the colorprimary component could theoretically be expectable. From the perspective of the targeted electric-driven white-light, one feasible approach can rely on the insufficient color-primary component of the organo-Sm ${ }^{3 b}$ complex, where its WOLEDs/WPLEDs generation, should be strictly dependent on the organo$\mathrm{Sm}^{3 b}$-included multi-component emitters or multiple-layering fabrication. As an alternative one, based on the single-component organo-Sm ${ }^{3 \mathrm{~b}}$-emitter with the straightforward white-light, the realization of its WOLEDs/WPLEDs could be superior, owing to the significantly simplified structure without additional color supplementation. Herein, in light of the pioneered dichromatic WOLED [7] fabricated with NPB-[Sm(DBM) 3 (phen)] (NPB $1 / 4 N^{N}, N^{0}$-di(naphthalen-1-yl)$N, N^{0}$-diphenyl-[1, $1^{0}$-biphenyl]-4, $4^{0}$-diamine, DBM $1 / 4$ dibenzoylmethane; phen $1 / 4$ 1,10-phenanthroline) co-deposited emitters, its stable and voltageindependent electroluminescent white-lights (CIE chromatic coordinates $x \frac{1 / 4}{4}$ $0.32-0.28$, y $1 / 40.28-0.33$ ), responsible from the single-component NPB$\left[\mathrm{Sm}(\mathrm{DBM})_{3}(\right.$ phen $\left.)\right]$ exciplex, are considerably attractive. Nonetheless, besides the vacuum-deposition high-cost, the WOLED still suffers from unsatisfactory electroluminescent performance $\left(\eta^{\max }{ }_{c} 1 / 40.17 \mathrm{~cd} / \mathrm{A}\right)$, which significantly inferior to the parameter for solid-state lighting [11], is even unsatisfactory enough to that $\left(\eta_{\mathrm{c}}>0.5 \mathrm{~cd} / \mathrm{A}\right)$ fundamentally required for low-cost portable full-color flat displays [12]. To circumvent the two issues above, herein, we envision a conceptual strategy of doping with specific organo- $\mathrm{Sm}^{3 \mathrm{~b}}$ complex and one suitable polymer to their solution-processed WPLEDs. On one hand, considering the efficient orange-light of $\left[\mathrm{Sm}(\mathrm{acac})_{3}\left(5-\mathrm{Br}-2,2^{\mathrm{O}}\right.\right.$-bpy) $]$ (2; Scheme

E-mail addresses: Ivxq@nwu.edu.cn (X. Lü),fgrnwu@126.com (G. Fu),

* Corresponding author. hhe@eiu.edu (H. He).

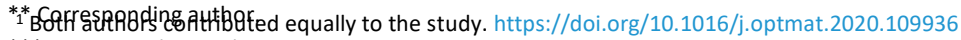

*** Corresponding author.

Received 15 January 2020; Received in revised form 11 March 2020; Accepted 20 April 2020 Available online 11 June 2020 0925-3467/(C 2020 Elsevier B.V. All rights reserved. 
1) and the excellent rheological property of blue-light-emitting PVK, the doping PVK@2 systems should endow an capability of directly dichromatic white-light for structure-simplified and solution-processable WPLEDs. On the other hand, the additional Forster $€$ energy transfer [13] from the PVK host to the guest ( $\left.\left[\mathrm{Sm}(\mathrm{acac})_{3}\left(5-\mathrm{Br}-2,2^{0}-\mathrm{bpy}\right)\right](2)\right)$ can be further motivated within the single-component PVK@2 systems, which, together with the balance of electron-transport and PVK-assisted hole-transport, probably give the improved electroluminescence of their cost-effective WPLEDs satisfactory enough for portable full-color flat displays [12].

\section{Experimental}

The information of starting materials and characterization methods was shown in the detailed Electronic Supporting Information (ESI). The ancillary ligand 5-Br-2,2'-bpy was obtained from the Stille coupling reaction [14] between 2,5-dibromopyridine and 2-(tributylstannyl) pyridine in the presence of $\mathrm{Pd}\left(\mathrm{PPh}_{3}\right)_{4}(0)$. As to the series of dihydrate $\mathrm{Ln}^{3 \mathrm{~b}}$-complex precursors [ $\mathrm{Ln}(\mathrm{acac})_{3}\left(\mathrm{H}_{2} \mathrm{O}\right)_{2}$ ] ( $\mathrm{Ln} 1 / 4 \mathrm{La}, \mathrm{Sm}$ or $\left.\mathrm{Gd}\right)$, they were synthesized according the well-established procedure from the literature [15].

\subsection{Synthesis of the ternary tris- 6 -diketonate- $L n^{3 \mathrm{~b}}$ complexes [ $\mathrm{Ln}$}

(acac) $\left.3\left(5-B r-2,2^{0}-b p y\right)\right](\operatorname{Ln} 1 / 4 \operatorname{La}(1) ; \operatorname{Ln} 1 / 4 \operatorname{Sm}(2)$ or $\operatorname{Ln} 1 / 4 \mathrm{Gd}(3))$

To a $\mathrm{MeOH}$ solution $(10 \mathrm{~mL})$ of the $\mathrm{Ln}^{3 \mathrm{~b}}$-complex precursor [ $\mathrm{Ln}$ (acac) $)_{3}\left(\mathrm{H}_{2} \mathrm{O}\right)_{2}$ ] $(0.2 \mathrm{mmol}$; $\mathrm{Ln} 1 / 4 \mathrm{La}$, Sm or $\mathrm{Gd})$, another $\mathrm{MeOH}$ solution $(10 \mathrm{~mL})$ containing 5-Br-2,2'-bpy $(0.2 \mathrm{mmol}, 0.047 \mathrm{~g})$ was added, and the resulting mixture was refluxed under a $\mathrm{N}_{2}$ atmosphere for another $3 \mathrm{~h}$. After cooling to room temperature, each of the obtained clear solutions was filtered, and left to stand for several days to afford the microcrystalline products 1-3, respectively. For $\left[\mathrm{La}(\mathrm{acac})_{3}\left(5-\mathrm{Br}-2,2^{0}-\mathrm{bpy}\right)\right](1)$ : Yield: $0.046 \mathrm{~g}, 69 \%$. Anal. Calcd for $\mathrm{C}_{25} \mathrm{H}_{28} \mathrm{~N}_{2} \mathrm{O}_{6} \mathrm{BrLa}$ : C, 44.73; $\mathrm{H}, 4.20 ; \mathrm{N}, 4.17 \%$. Found: $\mathrm{C}, 44.79 ; \mathrm{H}, 4.15 ; \mathrm{N}$, 4.21\%. FT-IR (KBr, cm ${ }^{1}$ ): 3005 (w), 2359 (w), 2344 (w), $1587(\mathrm{~m}), 1516(\mathrm{~s}), 1449$ (m), 1373 (vs), 1364 (s), $1275(\mathrm{~m}), 1260(\mathrm{~m}), 1140(\mathrm{w}), 1121(\mathrm{w}), 1084(\mathrm{w})$, $1061(w), 1038(w), 1016(w), 1001(m), 935(w), 916(w), 841(w), 785(m)$, $764(\mathrm{~s}), 748$ (s), $669(\mathrm{~m}), 631(\mathrm{~m}), 530(\mathrm{w}) .{ }^{1} \mathrm{H}$ NMR (400 MHz, DMSO-d $): \delta$
1377 (vs), $1256(\mathrm{~m}), 1188(\mathrm{w}), 1015(\mathrm{~m}), 955(\mathrm{w}), 916(\mathrm{~m}), 851(\mathrm{w}), 754(\mathrm{~m})$, 671 (m), 608 (w), 530 (w). ESI-MS (in $\mathrm{CH}_{3} \mathrm{CN}$ ) m/z: $683.03(100 \%),[\mathrm{M} \mathrm{H}]^{\mathrm{p}}$.

For $\left[\mathrm{Gd}(\mathrm{acac})_{3}\left(5-\mathrm{Br}-2,2^{0}-\mathrm{bpy}\right)\right]$ (3): Yield: $0.054 \mathrm{~g}, 78 \%$. Anal. Calcd for $\mathrm{C}_{25} \mathrm{H}_{28} \mathrm{~N}_{2} \mathrm{O}_{6} \mathrm{BrGd}$ : C, 43.54; $\mathrm{H}, 4.09 ; \mathrm{N}, 4.06 \%$. Found: $\mathrm{C}, 43.59 ; \mathrm{H}, 4.15 ; \mathrm{N}, 4.01 \%$. FT-IR (KBr, cm ${ }^{1}$ ): 3005 (w), 2359 (w), 2342 (w), 1584 (s), 1514 (s), 1456 (m), 1435 (m), 1387 (vs), 1362 (m), 1312 (w), 1260 (s), 1138 (w), 1115 (w), 1092 (w), $1045(\mathrm{w}), 1015(\mathrm{~m}), 920(\mathrm{~m}), 851(\mathrm{w}), 791(\mathrm{~m}), 764(\mathrm{~s}), 750(\mathrm{~s}), 733(\mathrm{w}), 648$ (w), 528 (w). ESI-MS (in $\mathrm{CH}_{3} \mathrm{CN}$ ) m/z: 691.04 (100\%), [M H] $]^{\text {. }}$.

\subsection{Synthesis of the PVK@2 film-typed hybrid materials doped with the complex 2 into the PVK host with different mass ratios}

To a toluene solution $(30 \mathrm{~mL})$ containing the commercial PVK $\left(\mathrm{M}_{\mathrm{w}} 1 / 490000\right.$ $\mathrm{g} / \mathrm{mol}$; PDI $\left.1 / 4 \mathrm{Mw}_{\mathrm{w}} / \mathrm{Mn}_{\mathrm{n}} 1 / 41.5\right)$, the complex 2 at a stipulated mass ratio (10:1, 10:3 or $10: 5$; wt/wt) relative to the PVK was added, and the resultant mixture was continuously stirred at room temperature overnight. After removal of the solvent and cooling to room temperature, the mixture was spin-coated at $3000 \mathrm{rpm}$ on a clean quartz slide, and then dried in air. The almost similar film thickness of $90 \mathrm{~nm}$ was measured by ellipsometry through collecting data every 5 from 65 to 75 and fitted using a Cauchy film on a gold model. For the PVK@2 films: Yield: 96\% (10:1; wt/wt); 98\% (10:3; wt/wt) or 99\% (10:5; wt/wt). Representative FT-IR ( $\mathrm{KBr}, \mathrm{cm}^{1}$ ): 2956 (w), 2362 (w), 1638 (w), 1610 (s), 1594 (s), $1582(\mathrm{~s}), 1536(\mathrm{w}), 1490(\mathrm{~s}), 1438(\mathrm{~m}), 1396(\mathrm{w}), 1368(\mathrm{~m}), 1314(\mathrm{w}), 1275$ (w), $1229(w), 1074(\mathrm{~m}), 1022(w), 1003(\mathrm{~m}), 908(w), 841(w), 810(w), 789(w)$, 753 (vs), 692 (m), 650 (m), 631 (w), 598 (w), $511(\mathrm{w})$.

2.3. WPLEDs' fabrication and characterization

Using the synthesized PVK@2 film (10:1, wt/wt) with the straightforward solid-state white-light as the single-component emitting layer, its WPLED was fabricated through a typically solution-processed procedure, configuring with ITO/PEDOT:PSS (40 nm)/PVK@2 (90 nm)/ BCP (10 nm/TPBi (30 nm)/LiF (1 $\mathrm{nm}) / \mathrm{Al}(100 \mathrm{~nm})$. Among these materials, ITO (indium tin oxide) was the coated glass substrate, and PEDOT:PSS (poly(3,4ethylenedioxythiophene):poly(styrenesulfonate)) was used as the holeinjecting material. BCP (2,9-dimethyl-4,7-diphenyl-1,10-phenanthroline) acts as the hole-blocking layer, and TPBi (1, 3, 5-tris(2-N-phenylbenzimidazolyl))<smiles>CC(=O)CC(C)=O</smiles>

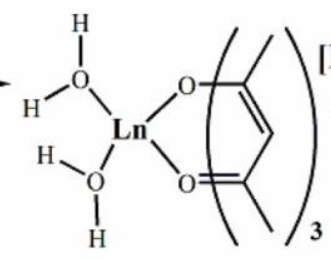

Hacac<smiles>CCCC[Sn](CCCC)(CCCC)c1ccccc1</smiles><smiles>Brc1ccc(Br)nc1</smiles>

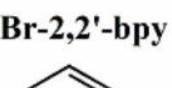<smiles>Brc1ccc(-c2ccccn2)nc1</smiles>

$\left[\mathrm{Ln}(\operatorname{acac})_{3}\left(\mathrm{H}_{2} \mathrm{O}\right)_{2}\right]$

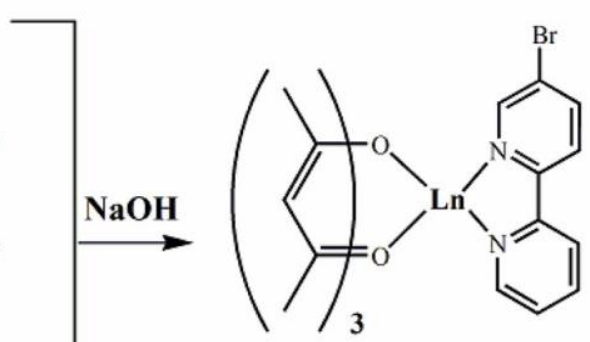

\section{$\left[\operatorname{Ln}(\text { acac })_{3}\left(5-B r-2,2^{\prime}-\right.\right.$ bpy $\left.)\right]$}

$$
\mathrm{Ln}^{3+}=\mathrm{La}^{3+}(1) ; \mathrm{Sm}^{3+}(2) ; \mathrm{Gd}^{3+}(3)
$$

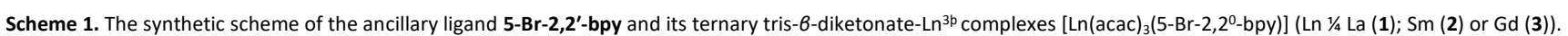
(ppm) $8.82(\mathrm{~d}, 1 \mathrm{H},-\mathrm{Py}), 8.70$ (d, 1H, -Py), 8.35 (t, 2H, -Py), 8.20 (q, 1H, -Py), 7.97

(t, 1H, -Py), 7.49 (q, 1H, -Py), $5.19\left(\mathrm{~s}, 3 \mathrm{H}_{1}-\mathrm{CH}^{-}-\mathrm{C}\right), 1.73\left(\mathrm{~s}, 18 \mathrm{H},-\mathrm{CH}_{3}\right)$. ESI-MS (in $\mathrm{CH}_{3} \mathrm{CN}$ ) $\mathrm{m} / \mathrm{z}: 670.02(100 \%)$,

$\left[\begin{array}{ll}\mathrm{M} & \mathrm{H}\end{array}\right]^{\mathrm{b}}$.

For [Sm(acac) $)_{3}\left(5-\mathrm{Br}-2,2^{0}-\right.$ bpy)] (2): Yield: $0.051 \mathrm{~g}, 75 \%$. Anal Calcd for $\mathrm{C}_{25} \mathrm{H}_{28} \mathrm{~N}_{2} \mathrm{O}_{6} \mathrm{BrSm}$ : C, 43.98; $\mathrm{H}, 4.13 ; \mathrm{N}, 4.10 \%$. Found: $\mathrm{C}, 43.91 ; \mathrm{H}, 4.18 ; \mathrm{N}, 4.14 \%$. FT-IR (KBr, cm $\left.{ }^{1}\right)$ : 2992 (w), 2359 (w), 2342 (w), $1584(\mathrm{~m}), 1514$ (s), $1456(\mathrm{~m})$, functions to facilitate the electron-transporting ability in the WPLED. The details of the WPLED's fabrication and testing are depicted in the Electronic Supporting Information.

\section{Results and discussion}

3.1. Synthesis, characterization and photo-physical property of the ternary tris-6-diketonate- $L n^{3 \mathrm{~b}}$ complexes 1-3 
Through the Stille coupling reaction [14] between 2,5-dibromopyridine and 2-(tributylstannyl)pyridine in the presence of $\mathrm{Pd}\left(\mathrm{PPh}_{3}\right)_{4}(0)$, the ancillary ligand $\mathbf{5}-\mathbf{B r}-\mathbf{2}, \mathbf{2}^{\prime}$-bpy was obtained in the yield of $67 \%$. Further based on the reaction of equimolar amount of the $\mathrm{Ln}^{3 \mathrm{~b}}$-complex precursor $\left[\mathrm{Ln}(\mathrm{acac})_{3}\left(\mathrm{H}_{2} \mathrm{O}\right)_{2}\right]$ ( $\operatorname{Ln} 1 / 4 \mathrm{La}, \mathrm{Sm}$ or Gd) [15] and the ancillary ligand 5-Br-2,2'-bpy, also as shown in Scheme 1, the series of ternary tris- $\mathbf{b}$-diketonate- $\mathrm{Ln}^{3 b}$ complexes $\mathbf{1 - 3}$ were obtained in $69-78 \%$ yields, respectively.

The complexes 1-3, soluble in common organic solvents, were well characterized by EA, FT-IR, ${ }^{1} \mathrm{H}$ NMR and ESI-MS. In the ${ }^{1} \mathrm{H}$ NMR spectrum of the anti-ferromagnetic $\left[\mathrm{La}(\mathrm{acac})_{3}\left(5-\mathrm{Br}-2,2^{\circ}-\mathrm{bpy}\right)\right](\mathbf{1})$, besides the combined proton resonances $\left(\delta \frac{1}{4} 8.82-1.73 \mathrm{ppm}\right.$ ) of both the deprotonated ligand (acac) ${ }^{-}$and the ancillary ligand 5-Br-2,2'-bpy in a stipulated molar ratio of 3:1, the enolic $-\mathrm{CH}^{-}-\mathrm{C}$ proton signal $(\delta 1 / 45.19 \mathrm{ppm})$ of the (acac)- ligand should be resulted from the $\mathrm{La}^{3 \mathrm{~b}}$-coordination. Moreover, the ESI-MS spectra of the complexes 1-3 exhibit a strong mass peak at $m / z 672.02$ for [ $\mathrm{La}(\mathrm{acac})_{3}(5-\mathrm{Br}-$ $2,2^{0}$-bpy)] (1), 683.03 for $\left[\mathrm{Sm}(\mathrm{acac})_{3}\left(5-\mathrm{Br}-2,2^{0}-\mathrm{bpy}\right)\right]$ (2) or 691.04 for $\left[\mathrm{Gd}(\mathrm{acac})_{3}\left(5-\mathrm{Br}-2,2^{0}-\mathrm{bpy}\right)\right]$ (3) assigned to the major species $[\mathrm{M} \mathrm{H}]^{\mathrm{b}}$, respectively. These observed results confirm that every ternary tris-6diketonate- $\mathrm{Ln}^{3 \mathrm{~b}}$ species of the complexes $\mathbf{1 - 3}$ can be retained in the respective solution.

The electronic absorption spectra of the two free ligands Hacac and $5-\mathbf{B r}-$ 2,2'-bpy and their ternary tris-6-diketonate- $\mathrm{Ln}^{3 b}$ complex 2-3 were recorded in dilute MeCN solutions as shown in Fig. 1. Owing to the $\mathrm{Ln}^{3 \mathrm{~b}}$-coordination, the complex 2-3 display the similar ligands-based while significantly broadened $(200-410 \mathrm{~nm})$ absorptions $\left(\lambda_{\mathrm{ab}} 1 / 4,247-248\right.$ and $\left.284-287 \mathrm{~nm}\right)$

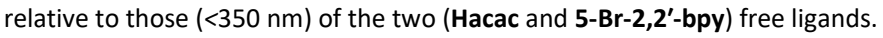
The molar absorption coefficients of the complexes 2-3 in the lower energy (284-287 nm) $\pi-\pi^{*}$-transitioned absorption bands are almost three orders of magnitude larger than those of the two (Hacac and $\mathbf{5}-\mathbf{B r}-\mathbf{2}, \mathbf{2}^{\prime}$-bpy) free ligands, which should be due to their ternary tris-6-diketonate- $\operatorname{Ln}^{36}$ component with the enhanced $\pi$-conjugation effect. For the $\mathrm{Sm}^{3 \mathrm{~b}}$-based complex 2, up photoexcitation of the chromohphores at the range of $200-410 \mathrm{~nm}\left(\lambda_{\text {ex }} 1 / 4340 \mathrm{~nm}\right)$, as shown in Fig. 2, the strong $\mathrm{Sm}^{3 \mathrm{~b}}$-centered characteristic emissions $(568 \mathrm{~nm}$ $\left({ }^{4} \mathrm{G}_{5 / 2} \rightarrow{ }^{6} \mathrm{H}_{5 / 2}\right.$ transition), $607 \mathrm{~nm}\left({ }^{4} \mathrm{G}_{5 / 2} \rightarrow{ }^{6} \mathrm{H}_{7 / 2}\right.$ transition), $652 \mathrm{~nm}\left({ }^{4} \mathrm{G}_{5 / 2} \rightarrow{ }^{6} \mathrm{H}_{9 / 2}\right.$ transition) and $712 \mathrm{~nm}\left({ }^{4} \mathrm{G}_{5 / 2} \rightarrow{ }^{6} \mathrm{H}_{11 / 2}\right.$ transition)) and the weak while detectable emission peaking at $\lambda_{\mathrm{em}} 1 / 4394 \mathrm{~nm}$ are concurrently observed. Moreover, besides the hyper- sensitive ${ }^{4} \mathrm{G}_{5 / 2} \rightarrow{ }^{6} \mathrm{H}_{9 / 2}$ electronic-dipole transition at $652 \mathrm{~nm}$, the intensity ratio between it and the ${ }^{4} \mathrm{G}_{5 / 2} \rightarrow{ }^{6} \mathrm{H}_{5 / 2}$ magnetic-dipole transition $\left(568 \mathrm{~nm}\right.$ ) is up to 4.9 , implying that the central $\mathrm{Sm}^{3 \mathrm{p}}$ ion of the complex $\left[\mathrm{Sm}(\mathrm{acac})_{3}\left(5-\mathrm{Br}-2,2^{0}-\mathrm{bpy}\right)\right](2)$ is located in a site without inversion symmetry [16]. And thus, the complex 2 emits a bright orange-light with the CIE (Commission International De L'Eclairage) chromatic

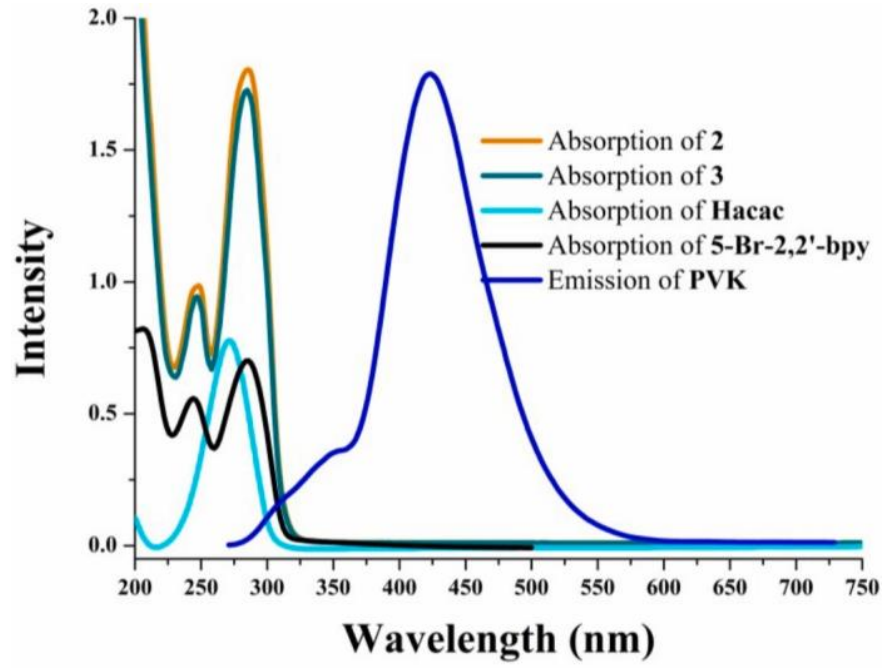

Fig. 1. The UV-visible absorption spectra of the 6 -diketone-typed ligand Hacac, the ancillary ligand $\mathbf{5 - B r}-\mathbf{2}, \mathbf{2}^{\prime}-$ bpy and their ternary tris-6-diketonate- $\mathrm{Ln}^{3 b}$ complexes $\mathbf{2 - 3}$ and the emission of PVK in dilute MeCN solution at room temperature.

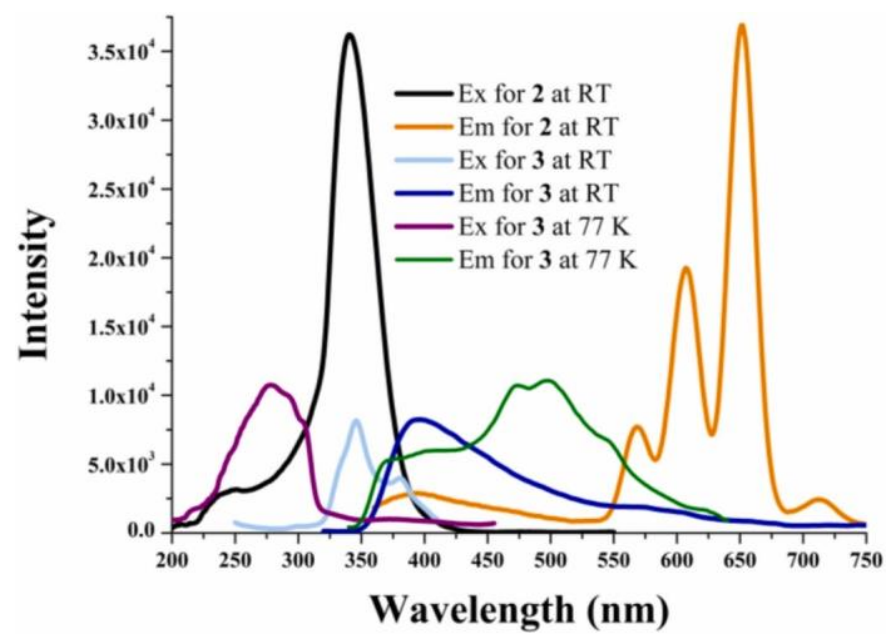

Fig. 2. The excitation and visible emission spectra of complexes $\left[\mathrm{Sm}(\mathrm{acac})_{3}\left(5-\mathrm{Br}-2,2^{0}-\mathrm{bpy}\right)\right]$ (2) and $\left[\mathrm{Gd}(\mathrm{acac})_{3}\left(5-\mathrm{Br}-2,2^{0}-\mathrm{bpy}\right)\right]$ (3) in dilute $\mathrm{MeCN}$ solution $\left(110^{5} \mathrm{M}\right)$ at room temperature or $77 \mathrm{~K}$.

coordinate $x 1 / 40.567$ and $y 1 / 40.349$.

As a reference compound, the $\mathrm{Gd}^{3 \mathrm{~b}}$-based complex 3 allows the further exploration of the antennae luminescence in the absence of energy transfer, because the $\mathrm{Gd}^{3 \mathrm{p}}$ ion has no energy levels below $32000 \mathrm{~cm}^{1}$, and therefore cannot accept any energy from the antennae excited state [17]. For the $\mathrm{Gd}^{3 \mathrm{p}_{-}}$ centered complex $\mathbf{3}$ in solution at room temperature, it shows the typically ligands-based fluorescence ( $\lambda_{\mathrm{em}} 1 / 4394 \mathrm{~nm}$ and $\tau 1 / 41.02 \mathrm{~ns}$ ) also shown in Fig. 2. By contrast, the $\mathrm{Gd}^{3 \mathrm{~b}}$-centered complex 3 displays the 0-0 transition phosphorescence $\left(\lambda_{\mathrm{em}} 1 / 4433 \mathrm{~nm}\right.$ and $\left.\tau 1 / 40.98 \mu \mathrm{s}\right)$ at $77 \mathrm{~K}$, from which, the triplet $\left({ }^{3} \pi-\pi^{*}\right)$ energy level of $23095 \mathrm{~cm}^{1}$ is obtained. With regard to the singlet $\left({ }^{1} \pi-\right.$ $\left.\pi^{*}\right)$ energy level $\left(27855 \mathrm{~cm}^{1}\right)$ estimated from the lower wavelength ( $359 \mathrm{~nm}$ ) of its UV-visible absorbance edge, the energy gap $\Delta E^{1}\left({ }^{1} \pi-\pi^{*}-{ }^{3} \pi-\pi^{*}, 4760 \mathrm{~cm}\right.$ 1; Fig. 1S) near to the desirable $5000 \mathrm{~cm}^{1}$, endows a relatively effective ISC process according to the Reinhoudt's empirical rule [18]. Meanwhile, ruled by the Latva's empirical rule [19], the second energy gap $\Delta E^{2}\left(5171 \mathrm{~cm}{ }^{1} ;{ }^{3} \pi-\pi^{*}\right.$ ${ }^{4} G_{5 / 2}$ ) between the ligands-based ${ }^{3} \pi-\pi *$ energy and the first excited state ${ }^{4} G_{5 / 2}$ $\left(17924 \mathrm{~cm}^{1}\right)$ of $\mathrm{Sm}^{3 \mathrm{p}}$ ion is large enough to sensitize the $\mathrm{Sm}^{3 \mathrm{~b}}$-centered orange-

light. Therefore, the radiative transition of the ${ }^{1} \pi-\pi^{*}$ energy, together with the following effective ${ }^{3} \pi-\pi^{*} \rightarrow{ }^{4} G_{5 / 2}$ transition of $S m^{3 b}$ ion, should be the reason to the dual emissions for the $\mathrm{Sm}^{3 \mathrm{~b}}$-based complex 2 . Further based on the lifetime-decayed experiments of the $\mathrm{Sm}^{3 \mathrm{p}}$-based complex 2 , the $\tau \frac{1 / 4}{4} 0.84 \mathrm{~ns}$ at $\lambda_{\mathrm{em}} 1 / 4394 \mathrm{~nm}$ ) for the weak ligands-based fluorescence and the $\tau 1 / 464 \mu \mathrm{s}$ at $\lambda$ em $1 / 4651 \mathrm{~nm}\left({ }^{4} \mathrm{G}_{5} / 2 \rightarrow{ }^{6} \mathrm{H} 9 / 2\right.$ transition) for the $\mathrm{Sm}^{3 \mathrm{p}}$-centered strong phosphorescence also verify its dual-emissive nature. Worthy of notice, the absolute quantum efficiency $\left(\Phi^{\mathrm{L}} \mathrm{sm}\right)$ of the complex $\mathbf{2}$ characteristic of the $\mathrm{Sm}^{3 \mathrm{~b}}$ centered orange-light is up to $5.8 \%$, which is at the top level among previously reported organo-Sm ${ }^{3 \mathrm{~b}}$-complexes $[5,6]$ for orange-light OLEDs.

\subsection{Color-tunable emissions included direct white-light of the PVK@2 film- typed hybrid materials with different mass ratios}

To realize the straightforward dichromatic white-light, the series of singlecomponent doping-typed hybrid materials PVK@2 with different mass ratios (10:1, 10:3 and 10:5; wt/wt) were obtained. In both of the FT-IR and PXRD (Fig. 2S) characterizations, the PVK@2 films exhibit the almost PVK-characteristic 
nature, which should be arisen from the low-concentration disperse of the complex $\mathbf{2}$ into the polymeric PVK. Moreover, for the representative PVK@2 film (10:1; wt/wt), its TG analysis result (Fig. 3S) shows the significantly improved decomposition temperature ( $T_{\mathrm{d}} 1 / 4389 \mathrm{C}$ at $5 \%$ weight loss) in comparison to that $\left(272 \mathrm{C}\right.$ ) of the complex 2 . Especially, the determined $T_{\mathrm{g}}$ (glass transformation temperature) of 195 C renders the PVK@2 film (10:1; wt/wt) a particular opportunity to its solution-processable WPLEDs.

Owing to the significant overlap (also Fig. 1) between the emission of the PVK host and the absorption of the complex 2 within the $280-310 \mathrm{~nm}$ range, effective Forster energy transfer [ $€$ 13] from the PVK host to the complex 2 should be motivated for the PVK@2 films. This range $\left(\lambda_{\text {ex }} 1 / 4280-310 \mathrm{~nm}\right)$ with every $10 \mathrm{~nm}$ step-size can be used the suitable excitation regime to realize the concurrent emissions of both the PVK-based blue-light and the orange-light of the complex 2 for the dichromatic-modulated white-light. Toward it, upon $\lambda_{\mathrm{ex}}$ $1 / 4$ 280-310 nm, the photo-luminescent properties of the PVK@2 films with different mass ratios $(10: 1,10: 3$ and 10:5; wt/wt) were examined at room temperature, and summarized in Figs. 3-4. For the PVK@2 film (10:1; wt/wt), photo-excitation at the range of $280-310 \mathrm{~nm}$, as shown in Fig. 3, gives rise to two-centered while broad-ranging emissions of $400-750 \mathrm{~nm}$ assigned to the PVK-based blue-light ( $422 \mathrm{~nm}$ ) and the $\mathrm{Sm}^{3 \mathrm{~b}}$-centered $\left({ }^{4} \mathrm{G}_{5 / 2} \rightarrow{ }^{6} \mathrm{H}_{\mathrm{J} / 2}\right.$ transitions; $J 1 / 45,7,9$ and 11) orange-light, respectively. Moreover, the two-centered relative intensity is strictly dependent on the excitation wavelength, where with the increase of the excitation wavelength, the orange-to-blue relative intensity ratio increases, correspondingly, indicating that effective Forster energy transfer [€ 13] from the PVK host to the complex $\mathbf{2}$ actually takes place. As expectable, the combination of the two-centered emissions leads to all the resultant colors (Points I-A-D; $x$ 1/4 0.255-0.277, y $1 / 40.196-0.198$ ) falling well within the white-light region. The CCTs of $1759-1917 \mathrm{~K}$ and the CRIs within 78-79, render the dichromatic-integrated colors characteristic of warmwhite-lights. Interestingly, the warm-white-lights are highly stable with little color-coordinate shifts $(|\Delta x|<0.03,|\Delta y|<0.01)$, which should be resulted from the $\mathrm{Sm}^{3 \mathrm{p}}$-centered orange-light-primary resource for the PVK@2 film (10:1; wt/wt). In particularly, excitation of $310 \mathrm{~nm}$ is found to produce the best

Fig. 4. The $\lambda_{\text {ex }}$-dependent emission spectra and corresponding CIE chromatic coordinates (in

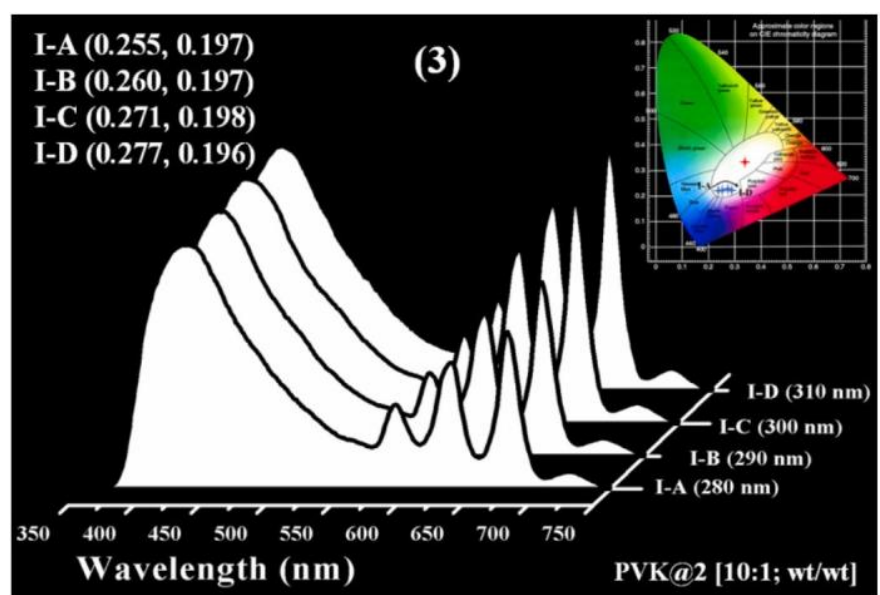

Fig. 3. The $\lambda_{\mathrm{ex}}$-dependent color-tuning white-light emissions and corresponding $\mathrm{CIE}$ chromatic coordinates (inset) of the solid-state PVK@2 film with (10:1; wt/wt) at room temperature. (For interpretation of the references to color in this figure legend, the reader is referred to the Web version of this article.) white-light (Point I-D; $x^{1 / 4} 0.277, y^{1 / 1 / 4} 0.196$, CCT of $1891 \mathrm{~K}$ and CRI of 79), whose quantum yield up to $6.7 \%$ is at the top level within previously reported organo$\mathrm{Sm}^{3 \mathrm{~b}}$-doping systems $[5,6]$ for orange-light OLEDs/PLEDs. Meanwhile, the 32 ns lifetime of PVK-incorporated blue-light $\left(\lambda_{\mathrm{em}} 1 / 4422 \mathrm{~nm}\right)$ and the $\mathrm{Sm}^{3 \mathrm{p}_{-}}$ decayed $\left(\lambda_{\mathrm{em}} 1 / 4651 \mathrm{~nm}\right)$ lifetime of $216 \mu \mathrm{s}$, confirm that the optimal whitelight (Point I-D) should unambiguously originate from the both fluorescence and phosphorescence dichromatic-incorporation.

Increasing the $\mathrm{Sm}^{3 \mathrm{~b}}$-doping content up to $10: 3(\mathrm{wt} / \mathrm{wt})$, also leads to the two-centered emissions shown in Fig. 4(a), while the domination of the $\mathrm{Sm}^{3 p_{-}}$ centered orange-light within, should be arisen from the relatively higher $\mathrm{Sm}^{3 p_{-}}$ doping content (10:3; wt/wt). Therefore, in contrast to the direct warm-whitelights (Fig. 3) for the PVK@2 film (10:1; wt/ wt), all the integrated colors upon $\lambda_{\text {ex }} 1 / 4280-310 \mathrm{~nm}$ are beyond the white-light regime, exhibiting the purplishpink lights (Points II-A-D; $x 1 \frac{1}{4} 0.371-0.443, y 1 / 40.243-0.275$ ). However, the pronounced $\mathrm{Sm}^{3 \mathrm{p}}$ - centered orange-lights render the $\lambda_{\mathrm{ex}}$-regulated purplishpink-emitting coordinates a relatively large shifts in the $|\Delta x|<0.8$ and $|\Delta y|<$ 0.4 ranges. Further increasing the doping content of the $\mathrm{Sm}^{3 \mathrm{~b}}$-based complex 2 for the PVK@2 film (10:5, wt/wt), the dichromatic integration of both the dominated $\mathrm{Sm}^{3 \mathrm{~b}}$-centered orange-light and the blue-light from the organic moiety (including PVK and the ligands-based residual) gives rise to the $\lambda_{\mathrm{ex}}$ regulated pink light (Fig. 4(b); Points III-A-D; $x$ 1/4 0.460-0.521, y1/40.292-0.316). Worthy of notice, the blue-light species of the PVK@2 films with different doping contents $(10: 1 ; 10: 3$ and 10:5; wt/wt), decay with an almost constant lifetime (32-34 ns), which should be arisen from the saturated colorcompensation [13] of the PVK host. By contrast, besides the non-multiple population of the ${ }^{4} \mathrm{G}_{5 / 2} \rightarrow{ }^{6} \mathrm{H}_{/ 2}$ transition hyper-sensitive intensity, the $\mathrm{Sm}^{3 b_{-}}$

decayed $\left(\lambda_{\text {em }} 1 / 4651 \mathrm{~nm}\right)$ phosphorescent lifetime $(\tau$ 1 1/4 $184 \mu \mathrm{s})$ for the PVK@2

film (10:5, wt/wt) is relatively shorter than those $\left(\tau \frac{1}{4} 212-216 \mu \mathrm{s}\right)$ with the lower doping concentrations, indicative of an occurrence of aggregationinduced quenching [3] with the 10:5 doping content.

\subsection{Electroluminescent performance of the single-component WPLED based on the PVK@2 film (10:1; wt/wt)}

To further elucidate the suitability of the PVK host for doping of the complex 2, the electrochemical property of the orange-light complex $\mathbf{2}$ in anhydrous MeCN solution was investigated and the HOMO and LUMO energy levels were calculated. In the cyclic voltammogram shown in Fig. $4 \mathrm{~S}$, an oxidation potential of $1.21 \mathrm{~V}$ versus $\mathrm{Fc}^{\mathrm{b}} / \mathrm{Fc}$ is detected, from which, the HOMO level of the complex $\mathbf{2}$ is estimated to be $5.47 \mathrm{eV}$. Despite no distinctive ) of the solid-state PVK@2 film with different mass ratios (10:3 (4a)

reduction wave for the complex 2 , a reasonable $E^{\mathrm{OPT}}{ }_{\mathrm{g}}$ of $3.45 \mathrm{eV}$ estimated from its absorbance edge ( $359 \mathrm{~nm}$, also Fig. 1) gives the LUMO level of 2.02 $\mathrm{eV}$. Both the HOMO and LUMO energy levels of the complex 2 fall within those ( 5.50 and $2.00 \mathrm{eV}$ ) of the PVK with shallow trap depths $(0.02-0.03 \mathrm{eV})$. This shows that the blue- light-emitting PVK characteristic of excellent holetransport is an ideal host for the doped complex 2.

On the other hand, in consideration of the inherently higher mobility $\left(10^{3}\right.$ $\left.\mathrm{cm}^{2} / \mathrm{V} \cdot \mathrm{s}\right)$ of holes than that $\left(10^{3} \mathrm{~cm}^{2} / \mathrm{V} \cdot \mathrm{s}\right)$ of electrons, the electrontransporting TPBi layer and the BCP layer functioning as the hole-blocking layer, are concurrently utilized to improve the carrier recombination. Therefore, based on the PVK@2 film (10:1; wt/wt) with 

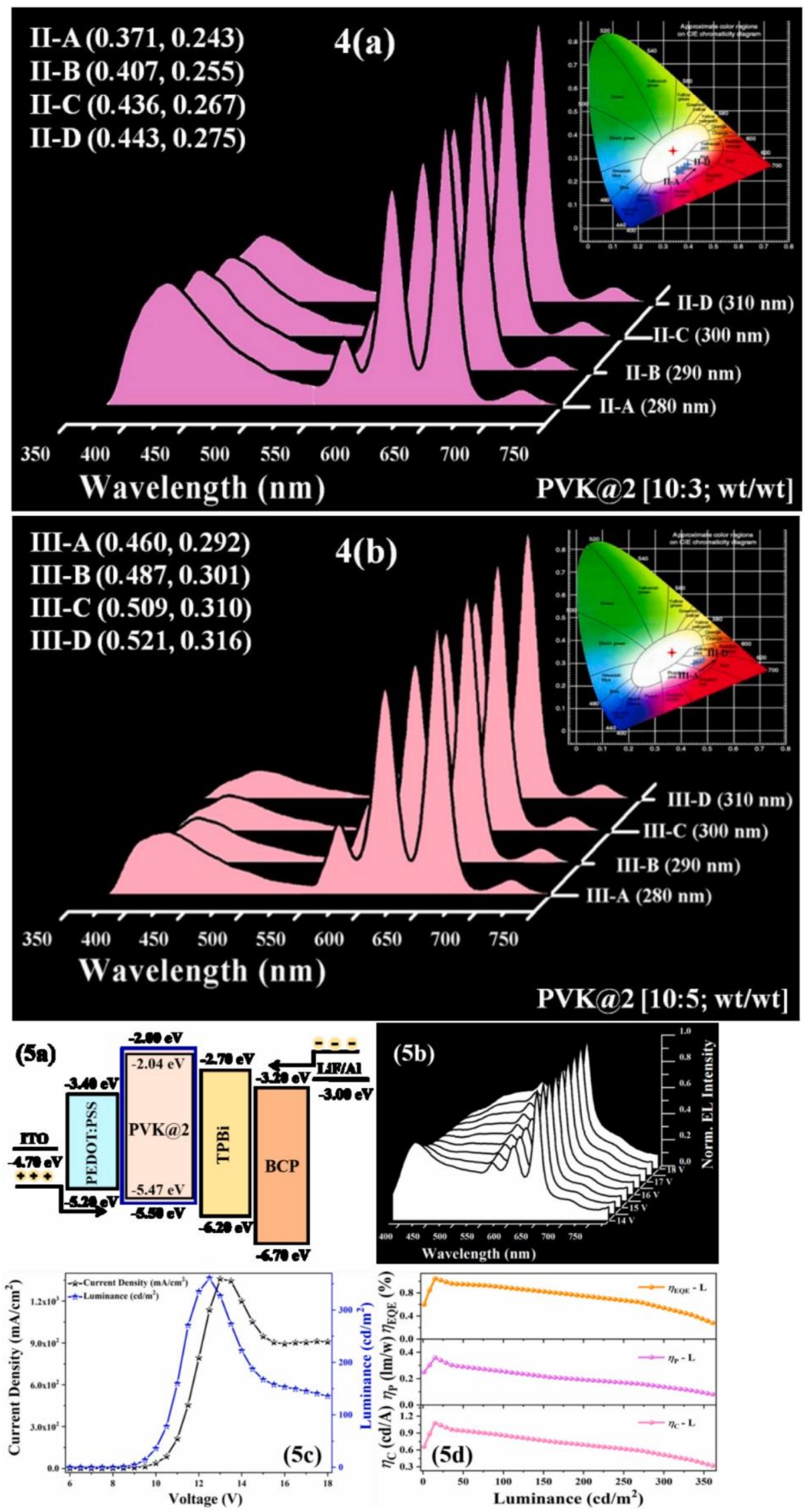

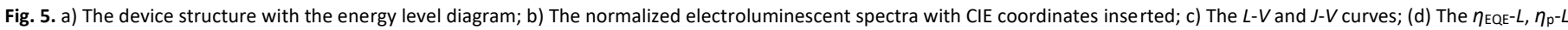
and $\eta_{c}-L$ curves for the WPLED based on the PVK@2 film (10:1; wt/wt).

and 10:5 (4b); wt/wt) at room temperature. 
the direct solid-state white-lights as the emitting layer, its single- component solution-processed WPLED was fabricated, and the electroluminescent performance was summarized in Fig. 5. According to the proposed energy level diagram for the WPLED shown in Fig. 5(a), the two HOMO levels ( 5.50 $5.47 \mathrm{eV}$ ) of PVK and the complex 2 are well between those ( $\left.6.20^{\sim}-5.20 \mathrm{eV}\right)$ of TPBi and PEDOT:PSS, and thus, the injected electrons and holes could be trapped and recombined within the whit-light-emitting species PVK@2 (10:1, $\mathrm{wt} / \mathrm{wt})$. As expected and shown in Fig. 5(b), the normalized electroluminescent spectra of the WPLED actually exhibit the simultaneous emissions of the PVK-based blue-light $\left(\lambda_{\mathrm{em}} 1 / 4422 \mathrm{~nm}\right)$ and the $\mathrm{Sm}^{3 \mathrm{~b}}$-centered $\left(\lambda_{\mathrm{em}} 1 / 4651 \mathrm{~nm}\right)$ orange-light throughout the whole applied bias voltage range $(6.0-18.0 \mathrm{~V})$. Meanwhile, their dichromatic integration gives rise to the electric- driven white-light. However, in contrast to the doping concentration and $\lambda_{\text {ex }}$-relative white-light production for the photo-luminescent PVK@2 film $(10: 1 ; \mathrm{wt} / \mathrm{wt})$, its electroluminescent white-lights are highly dependent on the applied bias voltages. Owing to the carrier- trapping mechanism during the electric-driven process, after the turn- on voltage $\left(V_{\text {on }}\right.$ at $\left.1 \mathrm{~cd} / \mathrm{m}^{2}\right)$ of $8.5 \mathrm{~V}$, the integrated white-lights (CIE chromatic coordinates $x$ 1/4 $0.257-0.287$, y $1 / 4$ $0.192-0.216)$ are highly stable within the applied bias voltages of 8.5-12 V, and then the higher applied bias voltages (12.5-18 V) render the white-lights' chromatic coordinates waving within a broadened range (CIE chromatic coordinates $x 1 \frac{1}{4}$ 0.299-0.363, y $\left.1 \frac{1}{4} 0.251-0.366\right)$. Despite the best white- light (CIE chromatic coordinate $x \frac{11}{4} 0.335, y \frac{1}{4} 0.303$, CCT of $5313 \mathrm{~K}$ and CRI of 84) occurring at $14 \mathrm{~V}$, it characteristic of a significantly increased orange-to-blue relative intensity ratio, should be the imbalanced carrier-transport with doping-induced phase-separation. As shown in Fig. 5(c), with the voltage increasing from $8.5 \mathrm{~V}$ to $12.5 \mathrm{~V}$, both the luminance $\left(L, \mathrm{~cd} / \mathrm{m}^{2}\right)$ and the current density $\left(J, \mathrm{~mA} / \mathrm{cm}^{2}\right)$ monotonously increase, and the $L^{\text {Max }}$ of $360.9 \mathrm{~cd} / \mathrm{m}^{2}$ is achieved at $12.5 \mathrm{~V}$ with a current density of $1136 \mathrm{~mA} / \mathrm{cm}^{2}$. Moreover, during that increase of the applied bias voltage or the luminance, as shown in Fig. $5(\mathrm{~d})$, all the efficiencies $\left(\eta_{\mathrm{c}}, \eta_{\mathrm{p}}\right.$, and $\left.\eta_{\text {EQE }}\right)$ increase first and insistently decrease with the $\eta^{\operatorname{Max}}{ }_{c}$ of $1.08 \mathrm{~cd} / \mathrm{A}$, the $\eta^{\operatorname{Max}}{ }_{\mathrm{p}}$ of $0.36 \mathrm{Im} / \mathrm{W}$ and the $\eta^{\operatorname{Max}}{ }_{\text {EQE }}$ of $1.05 \%$ at $9.5 \mathrm{~V}\left(L 1 / 415 \mathrm{~cd} / \mathrm{m}^{2}\right)$, respectively. Upon the applied bias voltage up to 12.5 $V$, the heavy (ca. 75\%) efficiency-roll-offs of the WPLED are observed, which should mainly be attributed to $\mathrm{Sm}^{3 \mathrm{~b}}$-centered phosphorescence lifetime being too long [6a]. Nonetheless, the single-component WPLED's performance (the $\eta^{\mathrm{Max}}{ }_{\mathrm{c}}$ of $1.08 \mathrm{~cd} / \mathrm{A}$, the $\eta^{\mathrm{Max}}{ }_{\mathrm{p}}$ of $0.36 \mathrm{~lm} / \mathrm{W}$ and the $\eta^{\mathrm{Max}}{ }_{\text {EQE }}$ of $1.05 \%$ ) is recordrenewed to those of previously organo-Sm ${ }^{3 \mathrm{~b}}$-based WOLEDs [7], and satisfactory enough to the requirements for portable full-color flat displays [12]. Further increasing the applied bias voltage ( $>12.5 \mathrm{~V})$, its significantly inferior performance should be attributed to the aging of the WPLED.

\section{Conclusions}

In summary, based on the efficient orange-light of the complex [Sm $\left.(\mathrm{acac})_{3}\left(5-\mathrm{Br}-2,2^{\circ}-\mathrm{bpy}\right)\right](2)$ and the blue-light of PVK as the color- primary components, the doping-typed PVK@2 films exhibit the doping concentration and $\lambda_{\text {ex }}$-relative dichromatic color-tuning (white- light to purplish-pink and to pink). Further using the PVK@2 film (10:1; wt/wt) with the straightforward white-light $\left(\Phi_{\mathrm{PL}} 1 / 46.7 \%\right)$ as the emitting layer, its single-component solutionprocessed WPLED exhibits gives the electroluminescent performance ( $L^{\operatorname{Max}}$ of $360.9 \mathrm{~cd} / \mathrm{m}^{2}, \eta^{\mathrm{Max}}{ }_{\mathrm{c}}$ of $1.08 \mathrm{~cd} / \mathrm{A}$ ) satisfactory enough for portable full-color flat displays.

\section{Declaration of competing interest}

The authors declare that they have no known competing financial interests or personal relationships that could have appeared to influence the work reported in this paper.

\section{Acknowledgements}

This work is funded by the National Natural Science Foundation (21373160, 21173165), the MOE Laboratory of Bioinorganic and Synthetic Chemistry, the
State Key Laboratory of Structural Chemistry (2019), the Postdoctoral Science Foundation (2018M633564), the Fundamental Research Fund for the Central Universities (G2018KY0308), the Graduate Innovation and Creativity Fund (YZZ17127) of Northwest University in China.

\section{Appendix A. Supplementary data}

Supplementary data to this article can be found online at https://doi. org/10.1016/j.optmat.2020.109936.

\section{References}

1. Zhang, Y. F.; Xu, Z.; Zhang, F. J.; Wang, Y.; Zhao, S. L., White organic light emitting device with dyestuff DCJTB mended in polymer. Spectroscopy and Spectral Analysis 2008, 28 (4), 760-762.

2. Watanabe, K.; Sakamoto, T.; Taguchi, M.; Fujiki, M.; Nakano, T., A chiral pi-stacked vinyl polymer emitting white circularly polarized light. Chem. Commun. 2011, 47 (39), 10996-10998.

3. Wang, R.; Peng, J.; Qiu, F.; Yang, Y. L., Enhanced white-light emission from multiple fluorophores encapsulated in a single layer of diblock copolymer micelles. Chem. Commun. 2011, 47, 2787-2789

4. Prakash, A.; Katiyar, M., White polymer light emitting diode using blend of fluorescent polymers. 16th International Workshop on Physics of Semiconductor Devices 2012, 8549.

5. $\quad$ Park, J. J.; Park, T. J.; Jeon, W. S.; Kim, S. Y.; Lee, Y. K.; Jang, J.; Kwon, J. H., White Polymeric Light-Emitting Diodes Based on Doping of an Orange Ir Complex in a Fluorene Blue Polymer Host. Mol. Cryst. Liq. Cryst. 2009, 498, 290-297.

6. $\quad$ Park, J. J.; Park, T. J.; Jeon, W. S.; Kim, S. Y.; Lee, Y. K.; Jang, J.; Kwon, J. H., White polymeric light-emitting diodes based on doping of an orange Ir complex in a fluorene blue polymer. Idw '07: Proceedings of the 14th International Display Workshops, Vols 1-3 2007, 1033-1036.

7. Nicolai, H. T.; Hof, A. J.; Blom, P. W. M., Charge transport in white light-emitting polymers. Organic Optoelectronics and Photonics li 2006, 6192.

8. Nicolai, H. T.; Hof, A.; Blom, P. W. M., Device Physics of White Polymer Light-Emitting Diodes. Adv. Funct. Mater. 2012, 22 (10), 2040-2047. 9. $\quad$ Li, B. N.; Liu, L.; Fu, G. R.; Zhang, Z.; Li, H. Y.; Lu, X.; Wong, W. K.; Jones, R. A., Color-tunable to direct white-light and application for white polymer light emitting diode (WPLED) of organo-Eu3+- and organo-Tb3+doping polymer. J. Lumin. 2017, 192, 1089-1095.

10. Shen, F. Z.; He, F.; Lu, D.; Xie, Z. Q.; Xie, W. J.; Ma, Y. G.; Hu, B., Bright and colour stable white polymer light-emitting diodes. Semiconductor Science and Technology 2006, 21 (2), L16-L19.

11. Kim, C.; Gwon, Y. J.; Kim, J.; Lee, T. S., Synthesis of fluorescent conjugated polymer nanoparticles and their immobilization on a substrate for white light emission. Polym Chem-Uk 2018, 9 (48), 5671-5679.

12. Amin, G.; Zaman, S.; Zainelabdin, A.; Nur, O.; Willander, M., ZnO nanorods-polymer hybrid white light emitting diode grown on a disposable paper substrate. Physica Status Solidi-Rapid Research Letters 2011, 5 (2), 71 73.

13. Taudt, C.; Baselt, T.; Oreski, G.; Hirschl, C.; Koch, E.; Hartmann, P., Cross-linking characterization of polymers based on their optical dispersion utilizing a white-light interferometer. Optical Measurement Systems for Industrial Inspection Ix 2015, 9525.

14. Song, H. J.; Shin, G. J.; Choi, K. H.; Lee, S.; Moon, D. K., White polymer light emitting diode materials introducing dendritic quinoxaline derivative: Synthesis, optical and electroluminescent properties. Synthetic Metals 2014, 190, 1-7.

15. Lee, H. K.; Kim, T. H.; Park, J. H.; Kim, J. K.; Park, O. O., Whitelight-emitting diodes using miscible polymer blend doped with phosphorescent dye. Organic Electronics 2011, 12 (6), 891-896. 16. Kim, J. H.; Song, W. S.; Yang, H., Color-converting bilayered composite plate of quantum-dot-polymer for high-color rendering white light-emitting diode. Opt. Lett. 2013, 38 (15), 2885-2888.

17. Kassamakov, I.; Ojala, K.; Salmia, A.; Haeggstrom, E.; Aaltonen, J.; Huber, A.; Saarikko, H.; Osterberg, M.; Oinonen, M., Characterization of dents and grooves on polymer films using scanning white light interferometry. Optical Micro- and Nanometrology in Microsystems Technology 2006, 6188. 
18. Inoue, A.; Hosokawa, T.; Haishi, M.; Ohtani, N., 4(dicyanomethylene)-2-methyl-6-(p-dimethylaminostyryl)-4H-pyran (DCM)doping density dependence of luminescence spectra and white emission in polymer light-emitting diodes. Physica Status Solidi C - Current Topics in Solid State Physics, Vol 6, No 1 2009, 6 (1), 334-337.

19. Hu, B.; Yao, C.; Huang, X. R., Designing of the White-Light Emission from a Single-Polymer System: Quantum Theoretical Study. Polymer Science Series A 2011, 53 (11), 1097-1105.

20. Fan, L. M.; Fan, W. L.; Li, B.; Zhao, X.; Zhang, X. T., W-shaped 1,3-di(2,4-dicarboxyphenyl)benzene based lanthanide coordination polymers with tunable white light emission. New J. Chem. 2016, 40 (12), 10440-10446.

21. da Silva, M. A. T.; Thomazini, E. F.; Albertini, M.; Renzi, W.; Franchello, F.; Dias, I. F. L.; Duarte, J. L.; Pocas, L. C.; Lourenco, S. A., Characterization of digital textile printing and polymer blend (PFODMP:P3HT) for application in manufacture of organic diodes emitting white light - WOLEDS. Optical Materials 2016, 62, 119-131.

22. Chen, M. X.; Sun, R. Y.; Ye, Y. C.; Tang, H. J.; Dong, X. Y.; Yan, J. L.; Wang, K. M.; Zhou, Q.; Wang, Z. L., Application of a novel red-emitting cationic iridium(III) coordination polymer in warm white light-emitting diodes. Optical Materials 2018, 76, 141-146.

23. Wang, R.; Peng, J.; Qiu, F.; Yang, Y. L.; Xie, Z. Y., Simultaneous blue, green, and red emission from diblock copolymer micellar films: a new approach to white-light emission. Chem. Commun. 2009, (44), 6723-6725. 24. Hrma, M.; Sichova, K.; Svoboda, J.; Vohlidal, J., Assembling of bis(tpy)fluorenes with Zn2+ and Fe2+ ions into metallo-supramolecular polymers with highly efficient white-light emission. Polymer 2017, 122, 22 33.

25. Chitara, B.; Bhat, S. V.; Vivekchand, S. R. C.; Gomathi, A.; Rao, C. N. R., White-light sources based on composites of GaN nanocrystals with conducting polymers and nanophosphors. Solid State Communications 2008, 147 (9-10), 409-413.

26. Cheng, G.; Fei, T.; Zhao, Y.; Ma, Y. G.; Liu, S. Y., White

phosphorescent polymer light-emitting devices based on a wide band-gap polymer derived from 3,6-carbazole and tetraphenylsilane. Organic Electronics 2010, 11 (3), 498-502.

27. Chen, S. A.; Chang, E. C.; Chuang, K. R.; Chao, C. I.; Wei, P. K.; Fann, W. S., Conjugated polymer blends as emitting layer for white light led. Abstr. Pap. Am. Chem. Soc. 1998, 215, U392-U392.

28. Zhen, H. Y.; Xu, W.; King, W.; Chen, Q. L.; Xu, Y. H.; Jiang, J. X.; Peng, J. B.; Cao, Y., White-light emission from a single polymer with singlet and triplet chromophores on the backbone. Macromol. Rapid Commun. 2006, 27 (24), 2095-2100.

29. Zhang, T. H.; Gong, Z. C.; Que, L., A white-light source operated polymer-based micromachined Fabry-Perot chemo/biosensor. 2009 4th leee International Conference on Nano/Micro Engineered and Molecular Systems, Vols 1 and 2 2009, 181-184.

30. Willander, M.; Nur, O.; Zaman, S.; Zainelabdin, A.; Bano, N.; Hussain, I., Zinc oxide nanorods/polymer hybrid heterojunctions for white light emitting diodes. J. Phys. D: Appl. Phys. 2011, 44 (22).

31. Wang, Z. W.; Gao, D. Z.; Ma, X. J.; Meng, J., White-Light Interferometry for Measuring Fuel Pressure in Icf Polymer-Microsphere Targets. Fusion Sci. Technol. 2014, 66 (3), 432-437.

32. Wang, B. Z.; Zhang, X. P.; Liu, H. M., White-light-emitting diode based on a single-layer polymer. Aip Advances 2013, 3 (5).

33. Tian, L. L.; Zhang, W.; Yang, B.; Lu, P.; Zhang, M.; Lu, D.; Ma, Y. G.; Shen, J. C., Zinc(II)-induced color-tunable fluorescence emission in the piconjugated polymers composed of the bipyridine unit: $A$ way to get whitelight emission. J. Phys. Chem. B 2005, 109 (15), 6944-6947.

34. Tang, K. C.; Tseng, S. R.; Li, W. S.; Meng, H. F.; Horng, S. F.; Hsu, C. S., Broad band and white phosphorescent polymer light-emitting diodes in multilayer structure. Synthetic Metals 2008, 158 (7), 287-291.

35. Sun, C.; Zhang, Y.; Sun, K.; Reckmeier, C.; Zhang, T. Q.; Zhang X. Y.; Zhao, J.; Wu, C. F.; Yu, W. W.; Rogach, A. L., Combination of carbon dot and polymer dot phosphors for white light-emitting diodes. Nanoscale 2015, 7 (28), 12045-12050.

36. Roberts, R. J.; Le, D.; Leznoff, D. B., Color-Tunable and WhiteLight Luminescence in Lanthanide Dicyanoaurate Coordination Polymers. Inorg. Chem. 2017, 56 (14), 7948-7959.
37. Qin, L. J.; Zhu, Y. C.; Yang, H.; Ding, L.; Sun, F.; Shi, M.; Yang, S. P., White-light phosphorescence from binary coordination polymer nanoparticles. Mater. Chem. Phys. 2013, 139 (2-3), 345-349.

38. Ovens, J. S.; Christensen, P. R.; Leznoff, D. B., Designing Tunable White-Light Emission from an Aurophilic Cu-I/Au-I Coordination Polymer with Thioether Ligands. Chemistry-a European Journal 2016, 22 (24), 82348239.

39. Niu, Y. H.; Liu, M. S.; Ka, J. W.; Bardeker, J.; Zin, M. T.; Schofield, R.; Chi, Y.; Jen, A. K. Y., Crosslinkable hole-transport layer on conducting polymer for high-efficiency white polymer light-emitting diodes. Adv. Mater. 2007, 19 (2), 300-+.

40. Niu, W. Y.; Sun, J. W.; Yan, P. F.; Li, Y. X.; An, G. H.; Li, G. M., 2D I-Di-toluoyl-tartaric acid Lanthanide Coordination Polymers: Toward Singlecomponent White-Light and NIR Luminescent Materials. Chemistry-an Asian Journal 2016, 11 (4), 555-560.

41. Nam, G. H.; Park, I. K., CdSe Quantum dot-conducting polymer hybrid structure for Phosphor-free white light-emitting diodes. Journal of the Korean Physical Society 2015, 66 (5), 785-789.

42. Meng, L. C.; Lou, Z. D.; Yang, S. Y.; Hou, Y. B.; Teng, F.; Liu, X. J.; $\mathrm{Li}, \mathrm{Y}$. B., White organic light-emitting diodes based on a combined electromer and monomer emission in doubly-doped polymers. Chinese Physics B 2012, 21 (8). 